Article

\title{
Multi-Objective Optimal Configuration of the CCHP System
}

\author{
Liukang Zheng, Xiaoli Wang *(D) and Baochen Jiang \\ School of Mechanical, Electrical and Information Engineering, Shandong University, Weihai 264209, China; \\ 201736344@mail.sdu.edu.cn (L.Z.); jbc@sdu.edu.cn (B.J.) \\ * Correspondence: wxl@sdu.edu.cn; Tel.: +86-138-6302-6640
}

Received: 26 February 2020; Accepted: 16 March 2020; Published: 19 March 2020

check for updates

\begin{abstract}
The combined cooling, heating and power (CCHP) system not only has high energy efficiency but also has different load structures. Traditional separate production (SP) system and power supply system do not consider the land cost in terms of the environmental benefits, and in the aspect of the power supply reliability, the grid-connected inverter cost is also ignored. Considering the deficiency of the traditional energy supply system, this paper builds the CCHP system construction cost model. The particle swarm optimization (PSO) is adopted to find out the minimum value of the construction cost, and the optimal system construction scheme is constructed from three aspects which are system reliability, economic benefits and environmental benefits. In this paper, the typical daily data, as well as the meteorological data and the load data, in the last four years are taken as experimental dataset. The experimental results show that compared with the traditional SP system and power supply system, the CCHP system established in this paper not only achieves lower cumulative investment cost, but also has a good power supply reliability and environmental benefits.
\end{abstract}

Keywords: microgrid; combined cooling; heating and power (CCHP) system; optimization; particle swarm optimization (PSO); reliability; environmental benefits

\section{Introduction}

With the rapid development of the global economy and the continuous improvement of people's living standards, the demand for energy is also apparently increasing. The shortage of fossil energy and the aggravation of environmental pollution make improving the efficiency of energy a more and more concerning problem. In order to solve the above problems, many scholars put forward the combined cooling heating and power (CCHP) system [1-3].

The CCHP system, built on the basis of energy ladder utilization, has a multi-structure energy supply mode, which mainly drives the gas turbine to generate electricity by consuming natural gas, and utilizes waste heat recovery equipment to recycle waste heat to improve the energy efficiency, realize the system's low-cost operation, ensure high energy supply reliability and good environmental protection. The efficient utilization of renewable resources (such as wind power and solar power) by CCHP system is an effective way to achieve sustainable development, energy conservation and emission reduction. Recently, this kind of comprehensive utilization of energy has been widely concerned by the academics $[4,5]$.

Compared with the single energy supply mode of the separate production (SP) system and the traditional power supply system, the CCHP system can not only improve the energy efficiency but also reduce the environmental pollution, and it is a power supply mode that is worth developing vigorously. Therefore, the significance of developing the CCHP system is as follows: (1) The system can improve the energy efficiency and optimize the energy structure. (2) High environmental benefits can realize the sustainable development of society. (3) The simultaneous supply of different energy can satisfy 
the requirements of the current power industry revolution and the peak regulation safety. Compared with SP system, CCHP system has the advantages of high energy efficiency and less environmental pollution. However, from the perspective of improving energy efficiency, reducing environmental pollution and enhancing the reliability of the system, the optimal configuration of the traditional CCHP system is still not perfect. Therefore, these three aspects are the key of the whole CCHP system configuration $[2,6-8]$.

$\mathrm{Hu}$ et al. set different economic benefits of the system as the research target, and based on the target, they have given different CCHP system configuration modes under different load structure requirements. However, the whole system fails to verify the reliability of the system based on the experimental data [9]. By improving the bacterial foraging algorithm, Ma et al. optimized the energy output device, which contains the wind storage hybrid microgrid and the light storage hybrid microgrid. However, the configuration process of the system not only did not consider the difference between the actual engineering load and the reservoir capacity load, but also ignores the relationship between energy device and the first-level load [10]. Li et al. optimized the configuration of the system from the aspect of energy analysis, economic benefits, and environmental benefits, and utilized two algorithms to compare the economic benefits under different scenarios to obtain the most suitable parameter configuration. Uncontrollable factors, such as the gas price fluctuation and the meteorological condition, make the whole system unreliable [11]. Wang et al. have constructed the entire system from the aspect of energy efficiency, investment cost and carbon emission. The CCHP system is compared with the SP system to highlight the economic and environmental benefits of cogeneration systems. Considering the uncontrollable factors, such as power and natural gas price fluctuation, the CCHP system performs better than the SP system in stability and reliability. However, the energy output characteristics of the uncontrollable energy output unit and the load characteristics of different energy supply periods are not analyzed, which makes the system unable to effectively avoid energy waste and reduce operating costs [12]. Wang et al. constructed the objective function from the perspective of generator set and device capacity However, the environmental cost of systematic land occupation is not considered [13]. Liu et al. first analyzed the structural characteristics of the system load and the operation characteristics of the equipment, and then used the integer linear programming method to solve the objective function. Finally, they completed the optimal design of the system. However, the CCHP system ignores the cost of grid-connected inverter equipment [14].

Since the current CCHP system does not fully consider the system configuration cost, system operation cost, system reliability evaluation matrices, environmental protection evaluation matrices and economic benefit evaluation matrices in the system construction process, there is still room for improvement in the optimal configuration of the system. Specifically, by optimizing the configuration of the traditional energy supply system, this paper proposes the CCHP system. The construction process of the proposed CCHP system is as follows: first, according to the energy price, the energy scheduling flowchart is given in Figure A1. Second, the constructed objective function and the constraint conditions are adopted to generate the system construction cost model. As the input data, the load date and the meteorological date are put into the system. Third, by analyzing the characteristics of the load, the photovoltaic's (PV's) energy output and wind turbine's (WT's) energy output under different conditions, the proposed system can avoid the improper device configuration, and has better stability when the system is built. Fourth, the improved particle swarm optimization (PSO) is adopted to find out the minimum value of the objective function. Finally, the evaluation metrices are adopted to evaluate the performance of the system. The proposed CCHP system is compared with the traditional SP system and power supply system, and the experimental result shows that the proposed CCHP system has lower cumulative investment cost, higher environmental benefits, and better power supply reliability. 


\section{The Construction of CCHP System}

The energy transfer diagram of the proposed CCHP system is shown in Figure 1. The energy output equipment in the system mainly includes the photovoltaic (PV), the wind turbines (WTs), the gas turbines (GTs), the battery (such as $\mathrm{LiCoO} 2$ ), the direct-fired lithium bromide absorption cold/warm water units (DLB), the energy storage device (ESD), the electric refrigerator (ER), and the electric boiler (EB) $[15,16]$.

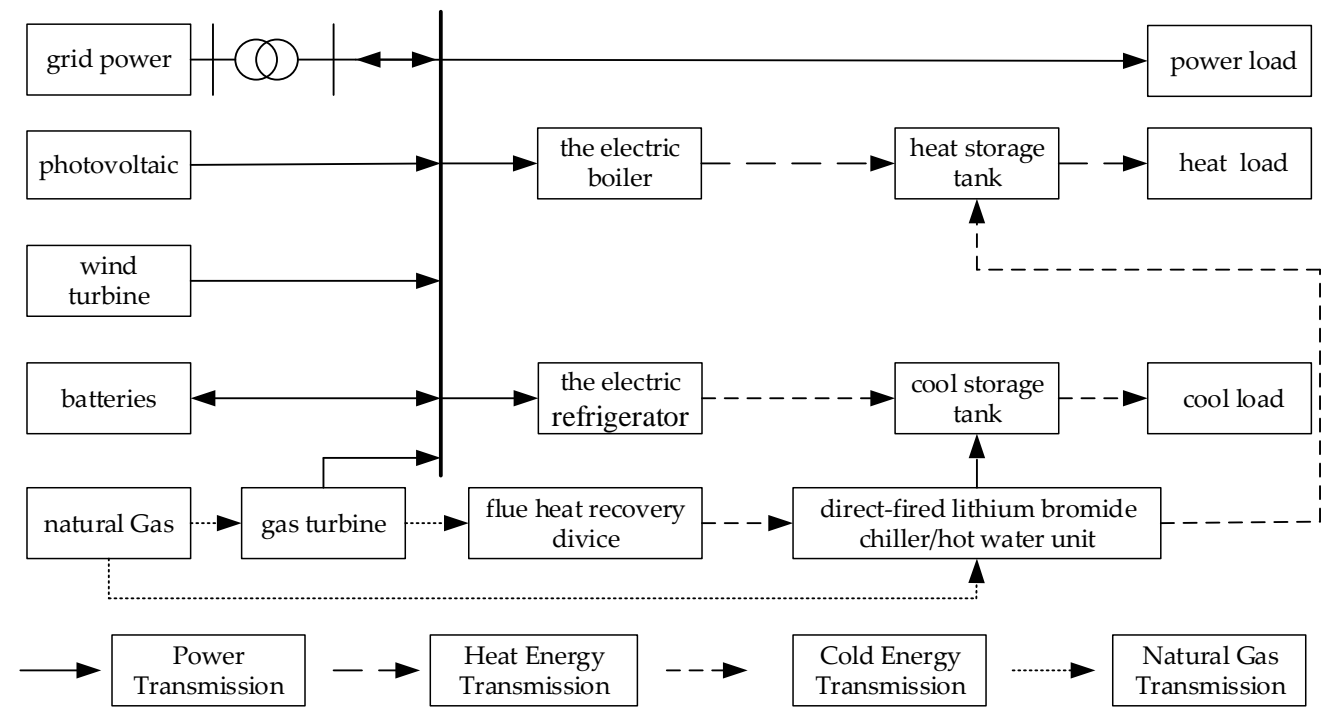

Figure 1. Energy transfer diagram of the proposed combined cooling heating and power (CCHP) system.

Figure 1 indicates that the proposed CCHP system can run in parallel mode and island mode. In parallel mode, when the power produced by the system is insufficient, the rest of power can be purchased from the grid power. The power is sold to the grid power when it is adequate. In the island mode, all the energy can be generated by the system itself. When the CCHP system is working, the low-cost equipment, such as the PV and the WT are taken as the first energy output unit. When the energy provided by the first energy output unit is insufficient, GT and grid power can provide the residual energy. Energy requirement of the cooling and heating loads involved in the CCHP system can be satisfied by ER, EB and DLB. In the SP system, the power generation efficiency of the gas turbine is only about $30 \%$, and $60 \%$ of the energy contained in flue gas of GT is directly discharged into the atmosphere, which not only leads to environmental pollution, but also has a huge waste of resources. In the proposed CCHP system, DLB can generate energy to satisfy the load by recycling the flue gas of GT and burning natural gas [17]. As shown in Figure 2, based on the meteorological data, the device and fuel cost, the operating cost of each distribution generation (DG), the maintenance cost, and the power generation subsidy, the system can calculate the power generation cost in DG and the grid power $[18,19]$. From Figure 2, we can find that the power cost of the PV is minimal at any time. GT has the highest power cost in power consumption valley, and the power cost of grid power is highest in power consumption peak.

Through the waste heat energy recycle device, a lot of flue gas of GT system is put into the DLB to generate cooling energy in the cooling season and generate heat energy in the heating season. If the energy generated by the flue gas cannot satisfy the heating or cooling load, the natural gas consumed by DLB and the power consumed by ER and EB will provide the rest of the energy [20]. First, the unit of cooling energy and heat energy are converted into the unit of power, and then the energy cost generated by the system in each time is shown in Figure 3. As shown in Figure 3, the cost of cooling and heating energy generated by DLB is minimum when there is flue gas in the system, and because of consuming power, both the cost of cooling energy generated by ER and the cost of heating energy generated by EB are maximal. 


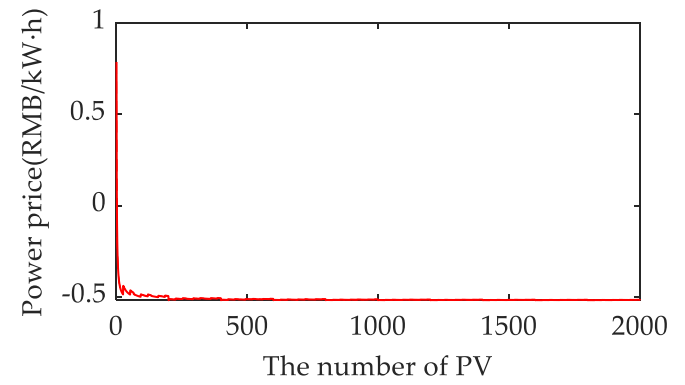

(a)

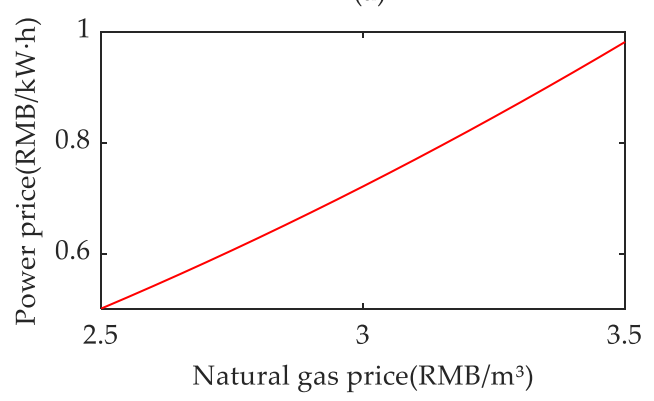

(c)

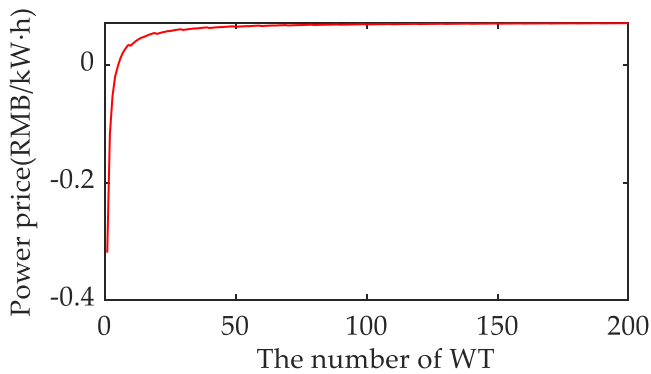

(b)

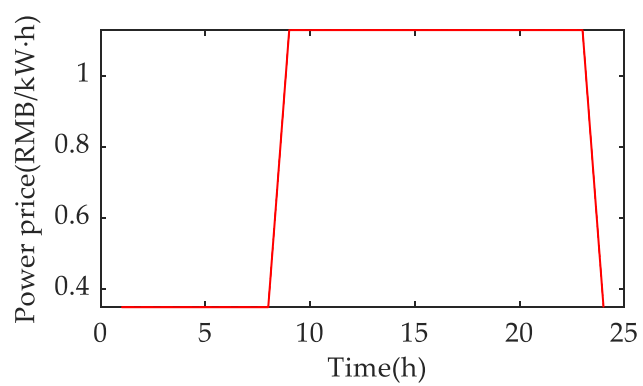

(d)

Figure 2. Power cost laws based on different methods. (a) The energy cost changing with the number of photovoltaics (PVs); (b) The energy cost changing with the number of wind turbines (WTs); (c) The power cost generated by gas turbines (GTs) changing with the natural gas price; (d) The power price at Yantai changing with different points in time.

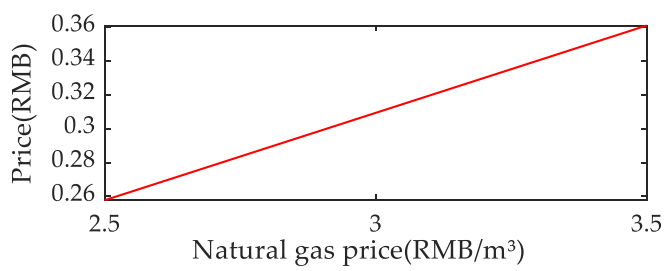

(a)

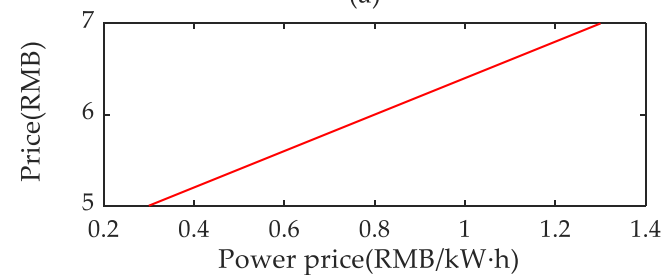

(c)

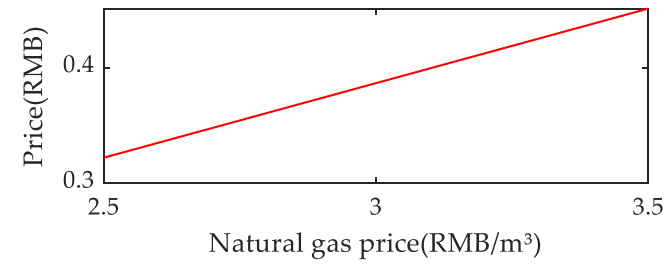

(e)

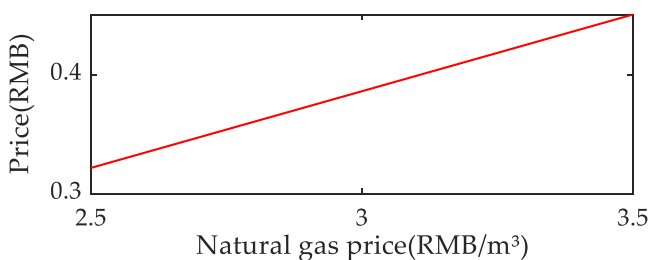

(b)

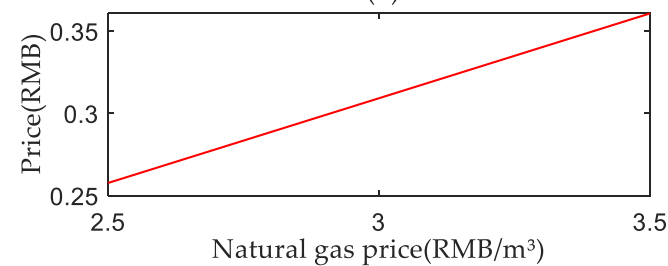

(d)

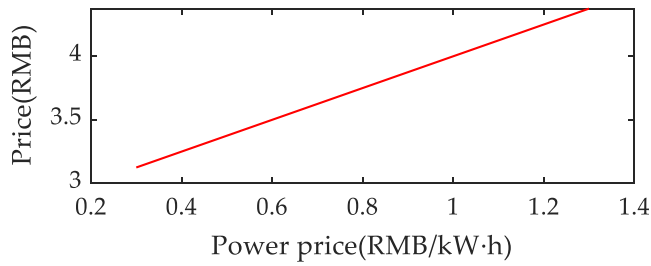

(f)

Figure 3. Heating and cooling energy cost per $1 \mathrm{~kW} \cdot \mathrm{h}$. (a) Cost of direct-fired lithium bromide absorption cold/warm water units (DLB) absorbing flue gas to produce cooling energy; (b) Cost of DLB consuming natural gas to produce cooling energy; (c) Cost of electric refrigerator (ER) consuming power to produce cooling energy; (d) Cost of DLB absorbing flue gas to produce heating energy; (e) Cost of DLB consuming natural gas to produce heating energy; (f) Cost of electric boiler (EB) consuming power to produce heating energy. 
According to the energy price generated by different energy output devices, the energy output sequence of different energy supply devices is shown in Appendix A. Considering the energy cost generated by the device shown in Figures 2 and 3, Appendix A indicates that the system preferentially selects the device with the lowest energy output cost in different energy supply time periods.

\section{The Optimal Configuration Model of the Proposed CCHP System}

\subsection{The Construction of the Objective Function}

In this paper, it should be noticed that the investment of system represents the cost of the system construction. The proposed objective construction cost function includes the cost of system equipment, the fuel cost, equipment maintenance cost of the system, the equipment installation cost, the environment cost and the system's revenue [21]. The detailed composition of the objective function in describe in Appendix B. According to the constraint conditions, the optimal configuration of the proposed CCHP system is aimed at finding out the minimum value of the investment objective function, and meanwhile, the system can perform well in multiple evaluation metrics.

\subsection{Constraint}

The constraint in the CCHP system can give the whole system a better operational reliability, economy benefits and environmental benefits. According to the IEEE Std 1366-2003 standard and the DLT836-2012 standard of China, the distribution network standard about the reliability is divided into three aspects, and they are the electrical component reliability, the load node reliability and the system's reliability. The system makes the reliability of the electrical component and load node $100 \%$ by increasing $C_{f i}$. To measure the system's reliability, this paper adopts the third level constraint [22]. In the process of system construction, according to the constraint conditions, the capacity of each device in the system can be figured out. During the operation of whole system, three constraint conditions which are power balance constraint, cooling energy balance constraint and cooling energy balance constraint should be considered. First, it is necessary to ensure the balance of power, the balance of cooling energy, and the balance of heating energy. Then, the system allocates energy to the related devices, which should satisfy their energy output constraint.

\subsubsection{Constraint of the Energy Storage Unit}

The mathematical model of the energy storage unit designed in the system includes the batteries which can store power, the hot water tank which can store heat energy, and the cool water tank which can store cooling energy. The power stored in a battery is related to the lifetime of it, and it directly affects the investment cost of the battery pack during the system's limited life [23]. The capacity of the battery system should satisfy

$$
(1-D O D) Q_{R} \leq Q_{B A T}(t) \leq Q_{B A T_{-} \max }
$$

where $Q_{B A T} \max (t)$ is the maximum capacity of the battery system; $Q_{B A T}(t)$ is the capacity of the battery system at time $\mathrm{t} ; Q_{R}$ is the rated capacity; $D O D$ is the maximum discharge depth.

The cooling storage system can achieve the purpose of storing cooling energy by constructing a water tank. Therefore, the capacity of the energy in the cooling storage system satisfies

$$
0 \leq \mathrm{Q}_{\text {cool }}(t) \leq Q_{\text {cool_max }}
$$

where $Q_{\text {cool_max }}$ is the maximum rated capacity of the cooling storage tank; $\mathrm{Q}_{\text {cool }}(t)$ is the capacity of the cooling storage tank at time $t$. 
The heating storage system can achieve the purpose of storing heating energy by constructing a water tank. Therefore, the capacity of the heating storage system can satisfy the formula shown in

$$
0 \leq Q_{h o t}(t) \leq Q_{h o t} \max
$$

where $Q_{\text {hot_max }}$ is the maximum rated capacity of the heating storage tank; $Q_{\text {hot }}(t)$ is the capacity of the heating storage tank at time $t$.

\subsubsection{Energy Supply and Demand Constraint}

The output energy should satisfy the demand of load to ensure the stable operation of the whole system at any time [24]. Constraint on power is shown in

$$
\sum_{\mathrm{i}=1}^{n} \sum_{\mathrm{t}=1}^{T} P_{\text {eq_power }}^{i} \Delta t \geq \sum_{t=1}^{T} P_{\text {load_power }}^{t}
$$

where $P_{\text {eq_power }}^{i}$ is the output power produced by the DG $i ; P_{\text {load_power }}^{t}$ is the demand of load node power at time t. Constraint on cooling energy is shown in

$$
\sum_{\mathrm{i}=1}^{n} \sum_{\mathrm{t}=1}^{T} P_{\text {eq_cool }}^{i} \Delta t \geq \sum_{t=1}^{T} P_{\text {load_cool }}^{t}
$$

where $P_{\text {eq_cool }}^{i}$ is the output of cooling produced by the device $i$; $P_{\text {load_cool }}^{t}$ is the demand of load node cooling energy at time $t$. Constraint on heating energy is shown in

$$
\sum_{\mathrm{i}=1}^{n} \sum_{\mathrm{t}=1}^{T} P_{\text {eq_hot }}^{i} \Delta t \geq \sum_{t=1}^{T} P_{\text {load_hot }}^{t}
$$

where $P_{\text {eq_hot }}^{i}$ is the heating energy produced by the device $i$; $P_{\text {load_hot }}^{t}$ is the demand of load node heating energy at time $t$.

\subsubsection{Constraint of Energy Output Equipment}

Since the energy output of the device has its own range, constraint of the energy output of the device can ensure the stable operation of the energy output unit. In the system construction, the constraint of the energy output unit is necessary to get the number of output units [24]. The energy output constraints in this paper are shown in

$$
\begin{gathered}
\mathrm{P}_{\text {power_min }}^{\mathrm{i}} \leq P_{\text {eq_power }}^{i}(t) \leq P_{\text {power_max }}^{i} \\
\mathrm{P}_{\text {cool_min }}^{\mathrm{i}} \leq P_{\text {eq_cool }}^{i}(t) \leq P_{\text {cool_max }}^{i} \\
\text { and } \mathrm{P}_{\text {hot_min }}^{\mathrm{i}} \leq P_{\text {eq_hot }}^{i}(t) \leq P_{\text {hot_max }}^{i}
\end{gathered}
$$

where $\mathrm{P}_{\text {power_min }}^{\mathrm{i}}$ and $P_{\text {power_max }}^{i}$ represent the maximum and minimum power output of DG $i$, respectively; $\mathrm{P}_{\text {cool_min }}^{\mathrm{i}}$ and $P_{\text {cool_max }}^{i}$ represent the maximum and minimum output of cooling energy output unit $i$, respectively; $\mathrm{P}_{\text {hot_min }}^{\mathrm{i}}$ and $P_{\text {hot_max }}^{i}$ represent the maximum and minimum output of heating energy output unit $i$, respectively. 


\section{The Optimization Configuration Evaluation Metrics of CCHP System}

\subsection{Reliability Evaluation Metric}

According to the international standard about reliability of distribution network described in Section 3.2, the reliability evaluation metric of the system should be higher than $99 \%$. The objective function of reliability metric is shown in

$$
\begin{gathered}
\eta_{\text {sys }}=\eta_{\text {eq }} \eta_{\text {gird }} \eta_{\text {power }} \\
\text { and } \eta_{\text {power }}=\prod_{i=1}^{N} \sum_{t=1}^{8760}\left(P_{\text {provide }}^{t}-P_{\text {load }}^{t}\right) / P_{\text {sys }}^{i}
\end{gathered}
$$

where $\eta_{e q}$ is the stability of the devices in the proposed CCHP system; in the system configuration, this paper selects some high-reliability components and adds spare components to make $\eta_{\text {eq }}$ achieve $100 \%$; $\eta_{\text {gird }}$ is the stability of load node; when the operation of whole system is stable, and the emergency equipment is added into the system, $\eta_{\text {gird }}$ is $100 \%$. $\eta_{\text {power }}$ is the reliability of the load in the system, $\mathrm{N}$ is the operational life of the system, $P_{\text {provide }}^{t}$ is the power produced by the system at time $t, P_{s y s}^{i}$ is the demand of system's load in the year $i$.

\subsection{Economic Evaluation Metric}

In this paper, the economic evaluation metric indicates that the cost of cumulative investment in the proposed CCHP system is lower than the cost of cumulative investment of SP system and traditional grid power. The cumulative investment cost of the CCHP system is

$$
\mathrm{C}_{\text {total }}^{\mathrm{CCHP}}=C_{f l}+C_{i n}+\sum_{\mathrm{i}=1}^{N} C_{s u}^{i}+C_{g a s}^{i}+C_{m a}^{i}+C_{e}^{i}+C_{\text {power }}^{i}
$$

where $N$ is the operational life of the system; $C_{\text {total }}^{C C H P}$ is the cumulative investment cost; $C_{s u}^{i}$ is the revenue of system in the year $i$; $C_{g a s}^{i}$ is the cost of fuel in the year $i ; C_{m a}^{i}$ is the cost of maintaining equipment in the year $i$; $C_{e}^{i}$ is the environmental cost in the year $i, C_{\text {power }}^{i}$ is the cost of purchasing power grid in the year $i$. The cumulative investment cost of the SP system is

$$
\mathrm{C}_{\text {total }}^{\mathrm{SP}}=C_{f l}+C_{i n}+\sum_{\mathrm{i}=1}^{N} C_{s u}^{i}+C_{\text {gas }}^{i}+C_{m a}^{i}+C_{e}^{i}+C_{\text {power }}^{i},
$$

where $\mathrm{C}_{\text {total }}^{\mathrm{SP}}$ is the cumulative investment costs of the SP system. The cumulative investment cost of traditional grid power systems is

$$
\mathrm{C}_{\text {total }}^{\mathrm{PG}}=\sum_{\mathrm{i}=1}^{N} \mathrm{C}_{e}^{i}+C_{\text {power }}^{i}
$$

where $\mathrm{C}_{\text {total }}^{\mathrm{PG}}$ is the cumulative investment cost of the traditional grid power.

\subsection{Environmental Protection Evaluation Metric}

SP, WT, and GT can produce the most of energy in the CCHP system, and as an auxiliary unit, the grid power interaction is adopted by the system. In China, $60 \%$ of power is generated by burning coal, and it will produce a large amount of pollutants, such as carbides, nitrides, and sulfides. The CCHP system will discharge pollutants when it is using energy generated by the grid power. According to the current cost of treating pollutants, the system takes the cost as the environmental one [25]. The environmental evaluation metric is the rate of pollutant reduction when the traditional grid power 
system and the SP system are replaced with the CCHP system in the industrial park. The environmental evaluation metric is shown in

$$
\eta_{\mathrm{e}}=\left(\sum_{\mathrm{j}=1}^{M} \alpha_{j} P_{s y s}-\mathrm{C}_{e}\right) / \sum_{\mathrm{j}=1}^{M} \alpha_{j} P_{\text {sys }} .
$$

\section{Experiment}

\subsection{Energy Supply and Demand Analysis of the CCHP System}

\subsubsection{Load Analysis}

This paper takes the demand of an industrial park's load in 2016 as an example. The total area of the industrial park is $2.05 * 10^{5} \mathrm{~m}^{2}$, and the average power load of the industrial park is about $350 \mathrm{~kW} \cdot \mathrm{h}$. Instead of joules, this paper uses kilowatt-hours to describe the cooling energy and heating energy. The industrial park's cooling load is about $218 \mathrm{~kW} \cdot \mathrm{h}$ in the cooling season (5.15-9.15 per year). The industrial park's heating load is about $115 \mathrm{~kW} \cdot \mathrm{h}$ in the cooling season (11.15-3.15 per year). According to different time periods and different load structures, these loads in the typical day are classified into five types: the power load in the heating season, the power load in the cooling season, the power load in transition season, heating load in heating season, and cooling load in cooling season. As shown in Figure 4, to find the energy demand characteristics of the five different loads, the energy demands for different loads over time are analyzed, and from Figure 4, we can find that when the load data is missing or abnormal, this paper utilizes the data of typical days to replace them. Therefore, the load analysis can make us find the method of reducing the equipment investment cost, and the method is very important to find an appropriate system configuration scheme.

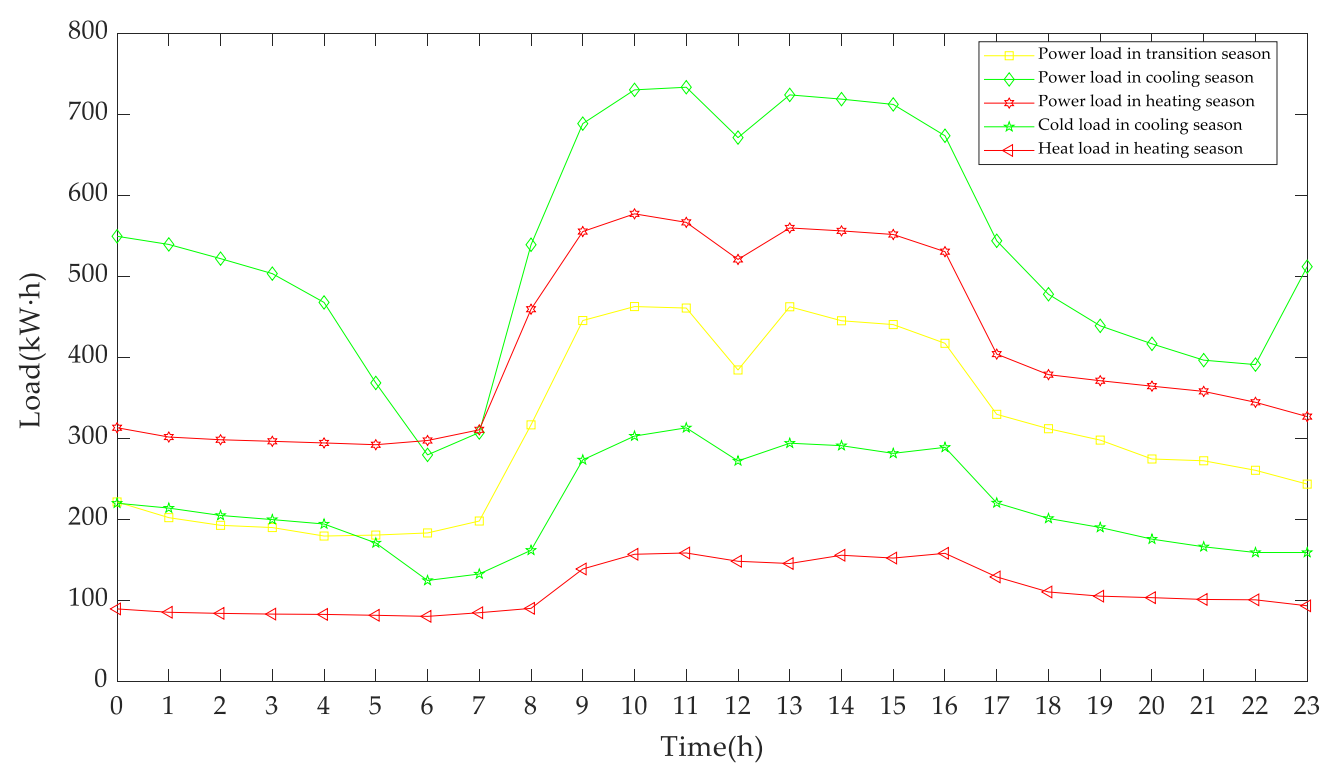

Figure 4. Power load, cooling load, and heating load in a typical day.

\subsubsection{The Power Output Analysis of Uncontrollable Unit}

The location of the proposed system is in Yantai, Shandong province. Based on the local meteorological data, such as wind speed and temperature in a year, PV and WT mathematical models are adopted to calculate their power output data and the power efficiency, which are $16.15 \%$ and $26.5 \%$ in Yantai, respectively [26]. According to the characteristics of WT and PV power output data in different energy supply seasons, the typical daily power output data of WT and PV is selected to make the system stable. Specifically, in the energy supply season, energy output data of typical day is utilized to replace the energy data of WT and PV, which is unreasonable and unnormal. When the 
power output data of PV and WT are accurate, the number of PV and WT are more reasonable and the power supply of the system is more reliable. The typical daily power outputs of WT and PV are shown in Figure 5.

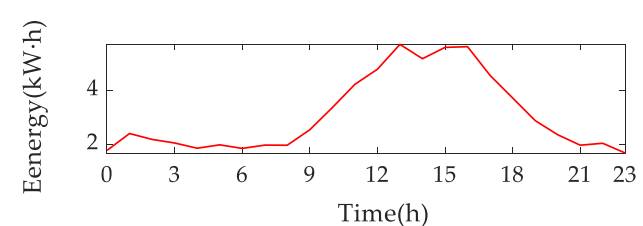

(a)

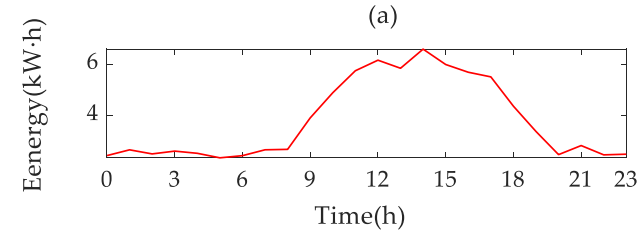

(c)

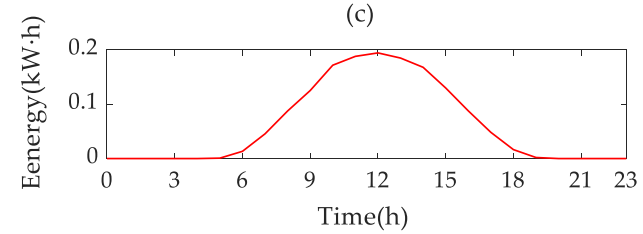

(e)

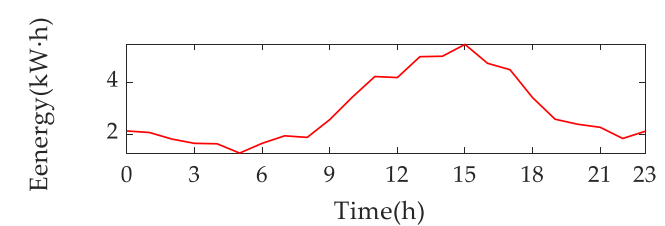

(b)

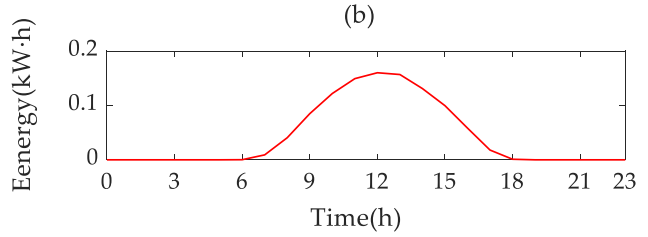

(d)

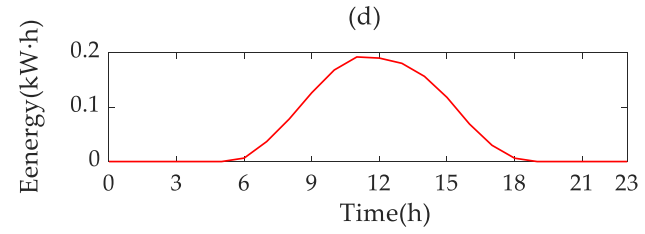

(f)

Figure 5. Different output energy of the separate production (SP) and WT in a typical day. (a) The power generated by a WT on a typical day in heating season; (b) The power generated by a WT on a typical day in cooling season; (c) The power generated by a WT on a typical day in transition season; (d) The power generated by a PV on a typical day in cooling season; (e) The power generated by a PV on a typical day in heating season; (f) The power generated by a PV on a typical day in transition season.

\subsection{Optimization Allocation of the System}

\subsubsection{Algorithm Analysis}

To solve the objective function, this paper adopts PSO. The advantages of PSO are random global search, fast convergence and high efficiency. The disadvantages of PSO is that the particles will miss the global optimal solution when the particles are submerged in the process of optimization. When this paper adopts the PSO to deal with multi-dimensional complex problems, the algorithm may have a local optimal solution which is called the premature convergence [27]. In order to avoid these problems in practical applications, scholars have proposed some improvement measures. This paper adopts the inertia weight method to improve the PSO [28]. The population particle velocity in the algorithm is shown in

$$
V_{i d}^{k+1}=\omega V_{i d}^{k}+c_{1} r_{1}\left(P_{i d}^{k}-X_{i d}^{k}\right)+c_{2} r_{2}\left(P_{g d}^{k}-X_{i d}^{k}\right) .
$$

The population particle position update formulas in the algorithm is shown in

$$
X_{i d}^{k+1}=X_{i d}^{k}+V_{i d}^{k+1} .
$$

As shown in the formula 16 and formula 17, $\omega$ is the inertia weight coefficient, which can determine the influence of the original speed on the current speed. In the process of solving function, a larger $\omega$ can enhance the global search of the PSO, and a smaller one can improve the local search capability. As the number of iterations increases during the execution of the algorithm, the range of the optimal solution will decrease. Therefore, it must be ensured that $\omega$ decreases as the number of iterations increasing. Formula 18 shows that the search area $X_{i d}^{k+1}$ will become smaller as $V_{i d}^{k+1}$ gradually becomes slower, 
and a good search method should start with a smaller range of the area. Finally, the optimal solution of the objective function is found out by PSO. The weight coefficient in this paper is determined by

$$
\omega(k)=\omega_{\text {star }}+\left(\omega_{\text {star }}-\omega_{\text {end }}\right)\left(2 k / T_{\max }-\left(k / T_{\max }\right)^{2}\right),
$$

where $\omega_{\text {star }}$ is the initial inertia weight; $\omega_{\text {end }}$ is the inertia weight when the number of iterations is maximum; $k$ is the current number of iterations; $\omega(k)$ is the weight coefficient in the iteration $k$.

\subsubsection{Model Solution}

According to the objective function in the Appendix B, the system construction cost model can satisfy all constraints, and it is shown in Figure 6. As shown in Figure 6, any point in space can make the system run reliably, and each point represents a system construction cost.

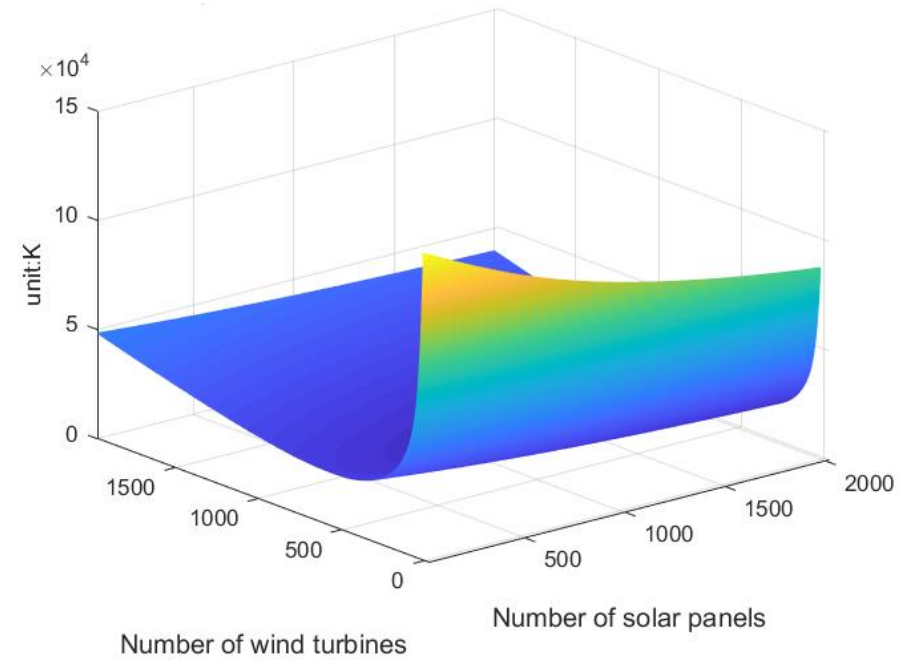

Figure 6. System construction cost model.

This paper adopts the improved PSO to find out the optimal value of the objective function, and makes the evaluation matrices described in Chapter 4 perform well. The optimal cost of the system is $3.385 * 10^{5} \mathrm{RMB}$, and the capacity of each device is shown in Table 1 .

Table 1. System capacity configuration parameters.

\begin{tabular}{cc}
\hline Name of the Energy Output Device & Installed Capacity $\mathbf{( k W \cdot h )}$ \\
\hline SP & 1140.4 \\
WT & 980 \\
GT & 325 \\
DLB & 260 \\
ER & 283 \\
EB & 268.7 \\
Battery & 1200 \\
Heating energy storage tank & 2000 \\
Cooling storage tank & 4500 \\
\hline
\end{tabular}

\subsection{Evaluation of the System}

\subsubsection{Evaluating Reliability of the System}

According to Formula 10 and Formula 11, the reliability of the system.is calculated in the proposed CCHP system. In this paper, based on the meteorological data and load data of the system location in 2016, the CCHP system satisfying load requirements was established. This paper adopts the 
data of 2016, 2017, 2018, and 2019 to calculate the differences between the required energy and the supplied energy and the system's reliability. Through analyzing and calculating the model of the CCHP system configuration with MATLAB software, the average daily missing load in the recent four years is $50.2053 \mathrm{~kW} \cdot \mathrm{h}, 49.5183 \mathrm{~kW} \cdot \mathrm{h}, 51.1643 \mathrm{~kW} \cdot \mathrm{h}$ and $50.9501 \mathrm{~kW} \cdot \mathrm{h}$, respectively. The more detailed differences are shown in Figure 7, and it indicates that there is no obvious load loss and the whole system is stable. In the last four years, the missing cooling load, heating load, power load and the value of system reliability in each year are shown in Figure 8. Figure 8 indicates that the energy supply reliability of the system satisfies the energy supply requirements of the industrial park in 2016, 2017, 2018 and 2019. According to the experimental conclusion, we can find that the energy supply reliability of the CCHP system in its lifetime can satisfy the energy supply requirements of the industrial park.
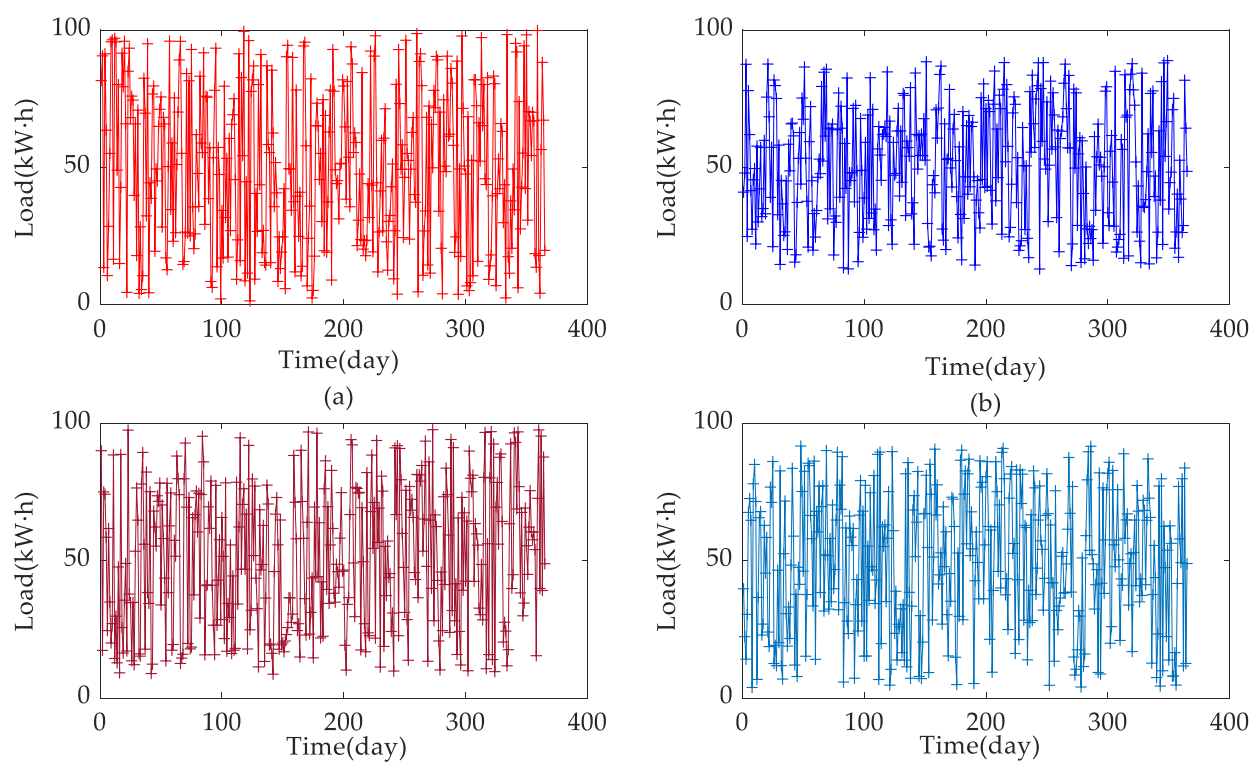

(c)

(d)

Figure 7. The loss of daily load. (a) The daily missing load in 2016; (b) The daily missing load in 2017; (c) The daily missing load in 2018; (d) The daily missing load in 2019.

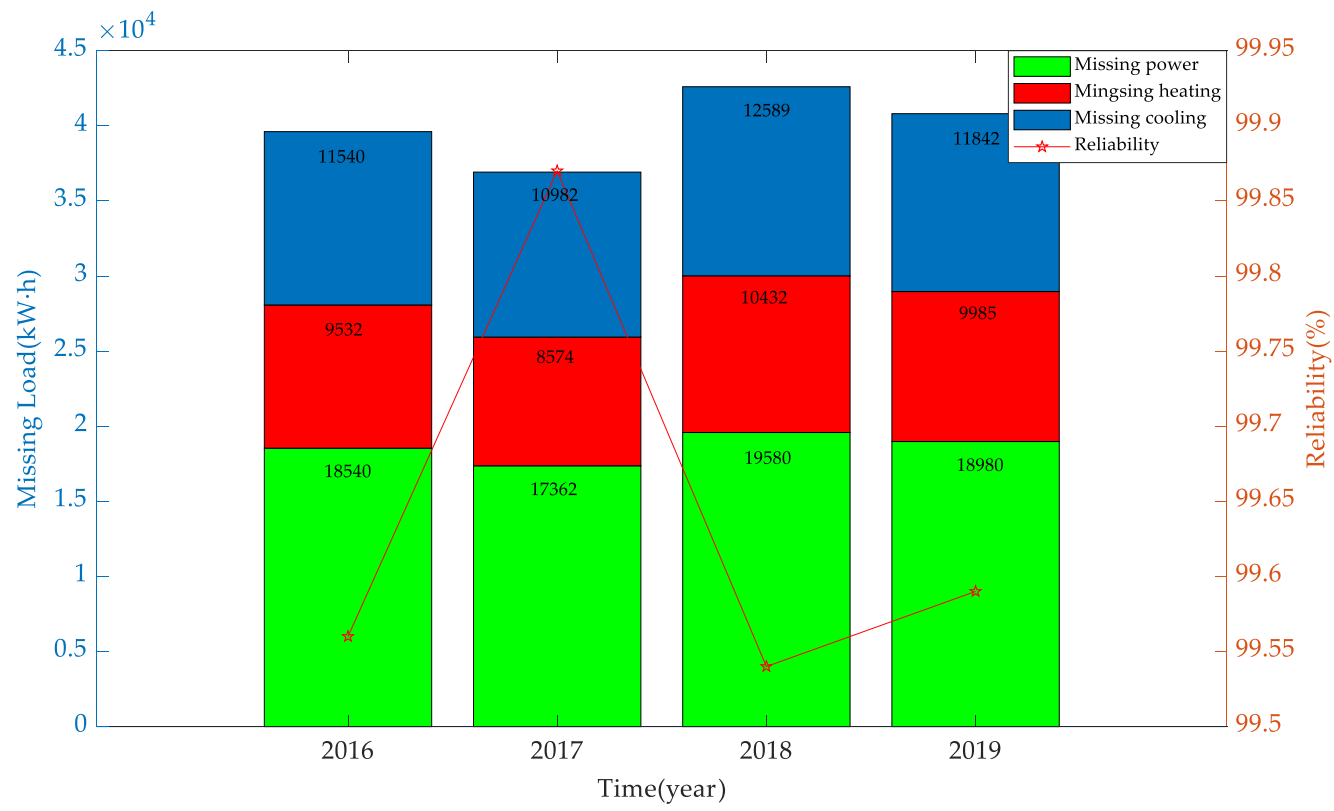

Figure 8. The missing cooling load in each year. 


\subsubsection{Evaluating the Economy Benefits of the System}

Through the study, this paper finds that the annual meteorological data of the same area are similar, and the annual growth rate of the load demand of the park is about $5 \%$. Average of the meteorological data and the load data in the last four years are respectively taken as the basic meteorological data and load data in the next two decades. Based on Formula (12), Formula (13), and Formula (14), the cumulative investment cost of the system is calculated, and the experimental results are shown in Figure 9, and it indicates that the proposed CCHP system and traditional grid power system have the highest and the lowest construction cost, respectively. Since CCHP system and SP system can get subsidies for new energy generation, the cumulative investment cost is gradually decreasing as the time increases. The CCHP system established in this paper has a lower cumulative investment cost than that of the traditional grid power system from the 13th year of the system's lifetime. In the 20-year lifetime of the system, the total investment cost in the CCHP system accounts for only $50 \%$ of the traditional grid power system. Compared with SP system, the investment cost of CCHP system increases apparently due to the increased secondary utilization of energy and other related equipment. In the CCHP system, most of the heating and cooling energy is obtained by recycling the exhaust gas of GT, and therefore, the CCHP system has a lower operation cost. From the 11th year of the system's lifetime, the total investment cost of the CCHP system is lower than that of the SP system. In summary, the proposed CCHP system performs best.

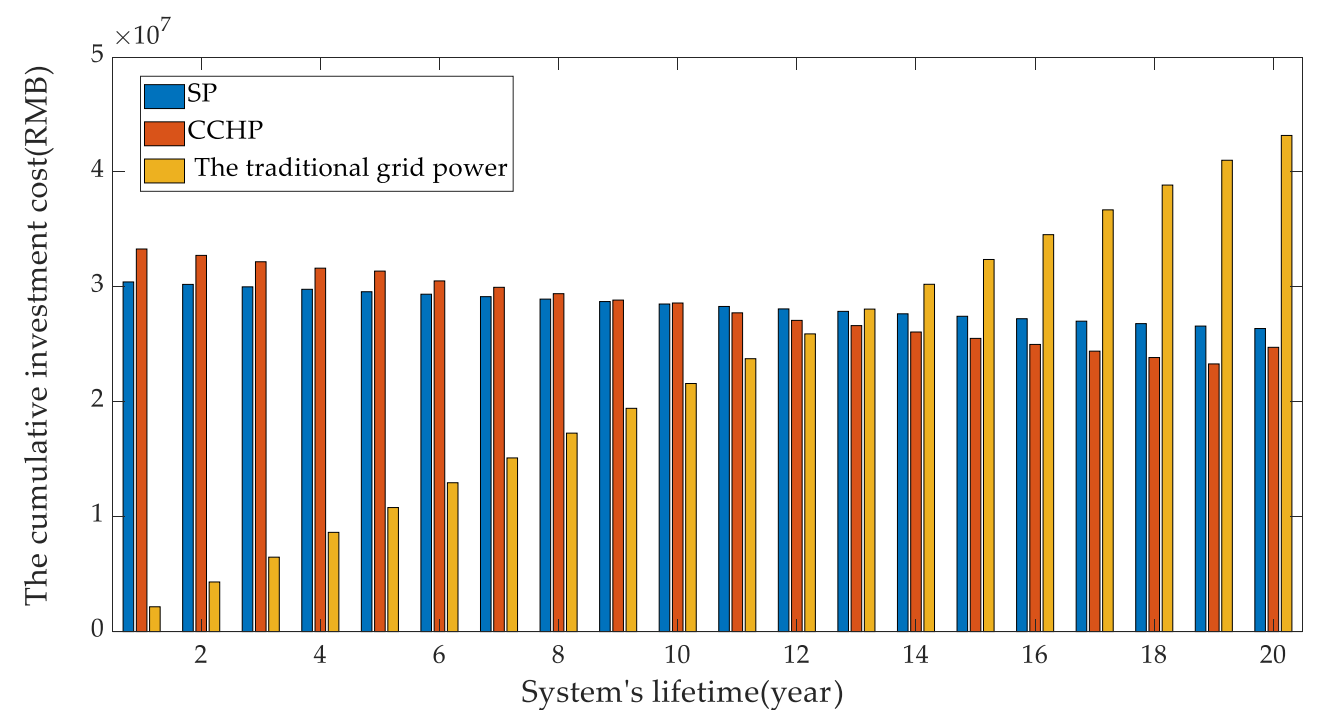

Figure 9. The cumulative investment cost of the proposed CCHP system, the SP and the traditional grid power system.

\subsubsection{Evaluating the System in Environmental Protection}

Formula B6 shows that when SP system, traditional power supply system and the proposed CCHP system satisfy the load demand of industrial parks, the annual environmental cost generated by these systems are 102606.98 RMB, 148979.6 RMB and 584923 RMB, respectively. Environmental cost generated by the power consumption of grid power, natural gas burning and occupied land is the main environmental cost. In the CCHP system, the power consumption equipment mainly includes ER, EB and industrial production equipment, and the natural gas consumption equipment mainly includes GT and DLB. In the SP system, the power consumption equipment mainly includes ER, EB and industrial production equipment, and GT is the main natural gas consumption equipment. In the power supply system, all energy is generated by consuming power, and therefore the equipment mainly includes ER, EB and industrial production equipment. Figure 10 indicates that the annual environmental costs of the industrial park in different energy supply modes. According to the environmental costs with different modes and Formula 15, we calculate the evaluation metrics in these three modes. Compared 
with the SP system and the traditional grid power system, the environmental evaluation metrics of the proposed CCHP system are approximately $31.26 \%$ and $82.45 \%$, respectively. Therefore, in the aspect of the environmental cost, the proposed CCHP system performs better than both the SP system and the traditional grid power system.

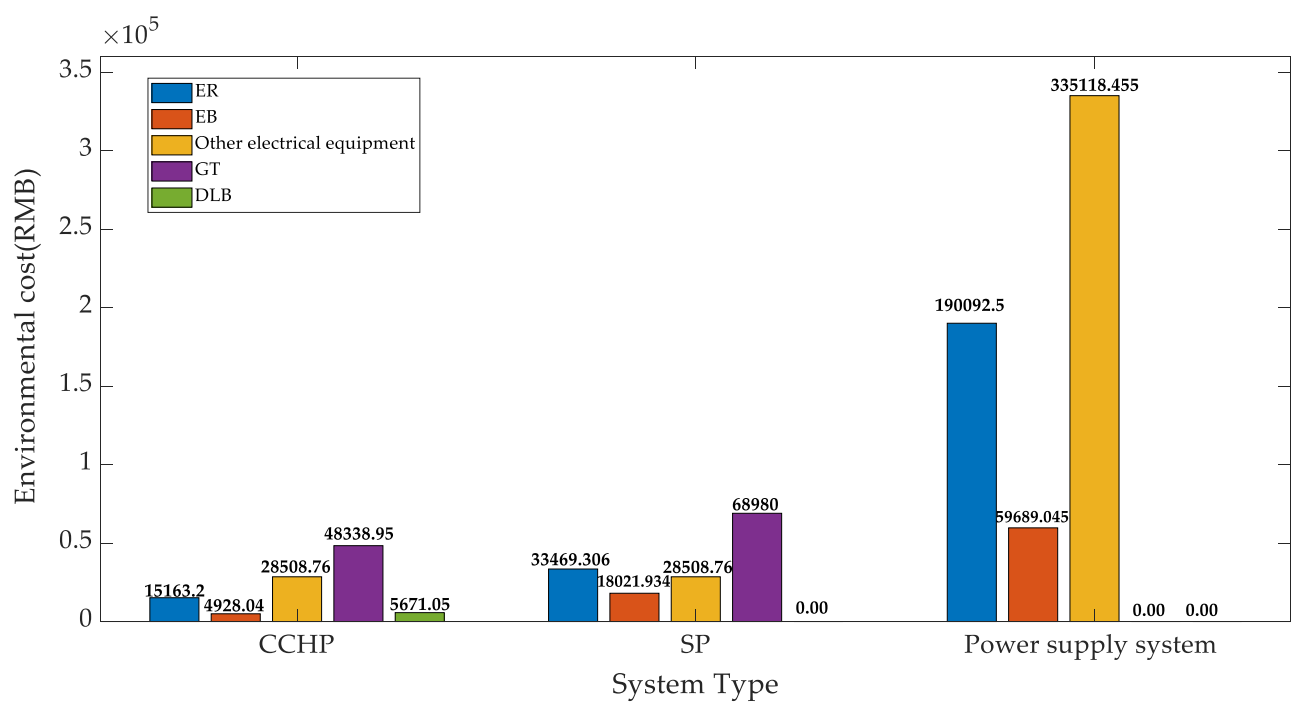

Figure 10. Environmental cost of the system among different energy supply modes.

\section{Conclusions}

In this paper, the multi-objective optimal configuration of the CCHP system is proposed. Compared with the SP system and the power supply system, the proposed CCHP system has lower cumulative investment cost, higher environmental benefits, and better power supply reliability. The possible reasons are as follows: (1) The combination of annual data and typical day data can more accurately reflect the actual use of renewable resources and loads, making the built system more reliable. (2) By calculating the energy supply cost of the equipment, the system can firstly choose the equipment with low energy supply cost, thus effectively improving the economic benefit of the CCHP system. (3) Different from the traditional CCHP system, this paper considers the land lease cost into the environmental cost. In the near future, we will make both long-term and short-term forecasts of the meteorological data to make more reliable use of wind power and solar power in the process of studying the configuration of CCHP system.

Author Contributions: Conceptualization, L.Z.; methodology, L.Z.; software, L.Z.; validation, X.W. and B.J.; formal analysis, L.Z.; investigation, L.Z.; resources, B.J.; data curation, L.Z.; writing-original draft preparation, L.Z.; writing-review and editing, X.W.; visualization, L.Z.; supervision, B.J.; project administration, X.W. and B.J. All authors have read and agreed to the published version of the manuscript.

Funding: The research received no external funding.

Acknowledgments: We gratefully acknowledge the technical assistance of DL850E ScopeCorder.

Conflicts of Interest: The authors declare no conflict of interest.

\section{Appendix A}

The energy output sequence of different energy supply devices is shown in Figure A1. In Figure $A 1, P_{p v}(t), P_{W T}(t), P_{M T}(t), P_{S O C}(t), P_{h_{-} \tan k}(t), P_{h_{-} B T_{-} M T}(t), P_{h_{-} B T_{-} G A S}(t), P_{h_{-} \text {power }}(t)$, $P_{C_{-} B T_{-} M T}(t), P_{C_{-} B T_{-} G A S}(t)$ and $P_{C_{-} \text {power }}(t)$ respectively represent the energy output of $S P$, the energy output of $W T$, the energy output of GT, the energy output of battery, the heat energy output of ESD, the heat energy output of DLB absorbing exhaust gas of GT, the heat energy output of DLB consuming natural gas, the energy output of EB, the cooling energy output of DLB absorbing exhaust gas of GT, the cooling energy output of DLB consuming natural gas, and the cooling energy output of ER. 


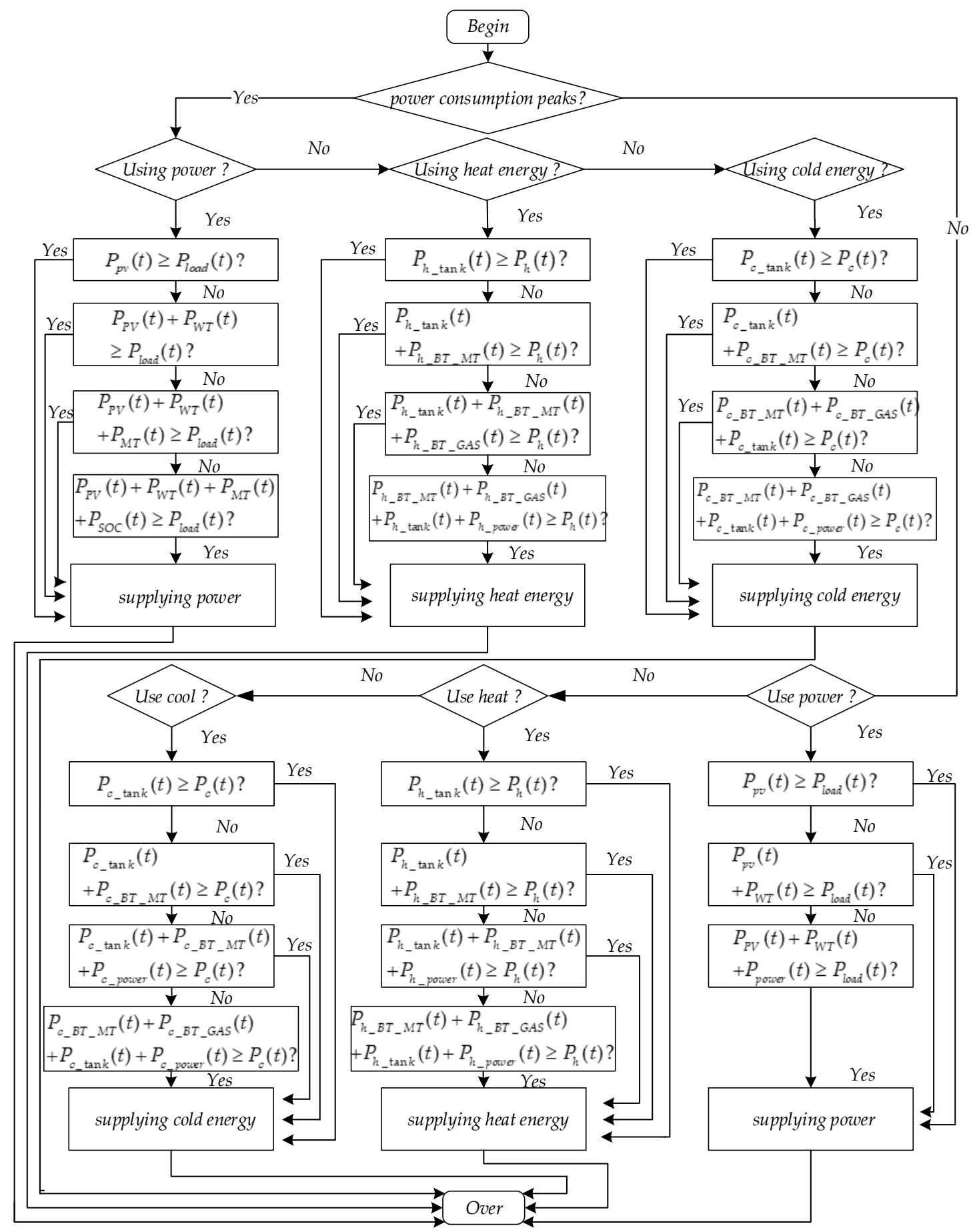

Figure A1. Energy scheduling flowchart of the proposed CCHP system.

\section{Appendix B}

The objective function of the system established in this paper is shown in

$$
\mathrm{C}_{\mathrm{total}}=C_{f i}+C_{g a s}+C_{m a}+C_{\mathrm{in}}+C_{e}+C_{s u}
$$

where $C_{\text {total }}$ is the investment cost of system; $C_{f i}$ is the cost of system equipment; $C_{g a s}$ is the fuel cost in the system; $C_{m a}$ is the equipment maintenance cost of the system; $C_{\text {in }}$ is the equipment installation cost; $C_{e}$ is environment cost; $C_{s u}$ is the system's revenue. 
The price of the equipment is corresponding to its capacity. The energy supply equipment and the grid-connected inverter are the main cost of system equipment, and it is shown in

$$
\mathrm{C}_{f i}=\sum_{\mathrm{i}=1}^{n}\left(C_{e q}^{\mathrm{i}} N U M_{e q}^{i}\left(P_{e q}^{i}\right)+C_{g c}^{i} N U M_{g c}^{i}\left(N U M_{e q}^{i}\left(P_{e q}^{i}\right)\right)\right)
$$

where $\mathrm{n}$ is the number of DGs; $C_{e q}^{\mathrm{i}}$ is the price of the equipment $i ; P_{e q}^{i}$ is the output power generated by the DG $i ; N U M_{e q}^{i}\left(P_{e q}^{i}\right)$ is the number of the DG $i ; C_{g c}^{i}$ is the price of the grid-connected inverter $i$; $N U M_{g c}^{i}$ is the number of the grid-connected inverter $i$.

Fuel cost includes the cost of natural gas consumed by GT and the cost of natural gas consumed by DLB when the exhaust gas energy of GT absorbed by DLB is insufficient to satisfy the load. The fuel cost in the system is shown in

$$
C_{\text {gas }}=\sum_{t=0}^{T}\left(\frac{P_{M T}^{t}}{\eta_{M T} L H V} \Delta t_{M T}+\frac{P_{B T_{\_} \text {gas_cool }}^{t}}{\eta_{B T_{-} \text {cool }} L H V} \Delta t_{B T_{-} \text {gas_cool }}+\frac{P_{B T_{-} \text {gas_hot }}^{t}}{\eta_{B T_{\_} h o t} L H V} \Delta t_{B T_{-} g a s_{\_} h o t}\right) C_{\text {gas }}^{t},
$$

where $\mathrm{T}$ is the time of the device's operation; $P_{M T}^{t}$ is the output power produced by GT at time $\mathrm{t} ; \eta_{M T}$ is the power generation efficiency of GT consuming natural gas; $L H V$ is the calorific value of natural gas which is $9.7 \mathrm{~kW} \cdot \mathrm{h} / \mathrm{m}^{3}$ in this paper; $\Delta t_{M T}$ is the running time of GT; $P_{B T_{-} \text {gas_cool }}^{t}$ and $P_{B T_{-} \text {gas_hot }}^{t}$ respectively represent the cooling energy and heat energy generated by DLB when it consumes natural gas at time $\mathrm{t} ; \eta_{B T}$ cool and $\eta_{B T}$ hot respectively represent the efficiency of cooling energy and heat energy generated by DLB when it consumes natural gas at time $\mathrm{t} ; \Delta t_{B T_{-} \text {gas_cool }}$ and $\Delta t_{B T_{-} g a s_{-} h o t}$ respectively represent the time of conditions when DLB group produces cooling energy and heat energy by consuming natural gas; $C_{g a s}^{t}$ is the price of natural gas at time $t$.

$C_{m a}$ includes the equipment maintenance cost in operation and the equipment periodic maintenance cost. $C_{m a}$ is shown in

$$
\mathrm{C}_{\mathrm{ma}}=\sum_{\mathrm{i}=1}^{\mathrm{n}}\left(K_{o \delta m}^{i} \Delta t \sum_{t=0}^{T}\left(P_{D G}^{t}+C_{D G}^{i}\right)\right)
$$

where $K_{o \delta m}^{i}$ is the equipment maintenance cost when the DG $i$ produces $1 \mathrm{~kW} \cdot \mathrm{h}$ energy; $P_{D G}^{t}$ is the output power produced by the DG at time $\mathrm{t} ; \Delta t$ is the time of the DG operation; $C_{D G}^{i}$ is the periodic maintenance cost of equipment $i$.

$C_{\text {in }}$ mainly includes equipment installation cost and the land lease cost, and it is shown in

$$
\mathrm{C}_{\mathrm{in}}=\sum_{i=1}^{n} N U M_{D G}^{i}\left(C_{i n}^{i}+S_{D G}^{i} C_{\text {land }}\right)
$$

where $C_{i n}^{i}$ is the cost of installing DG $i ; S_{D G}^{i}$ is the occupied land area of DG $i$; $C_{\text {land }}$ is land lease price.

When the CCHP system consumes natural gas and power generated from the grid power, it will indirectly generate carbides, nitrides, and sulfides, and dealing with these emissions will cause additional cost. Since the plant can purify pollutants when the leased land is not used as the industrial one, the land can also cause the additional environment cost. Therefore, $C_{\mathrm{e}}$ is shown in

$$
\mathrm{C}_{\mathrm{e}}=\sum_{i=1}^{\mathrm{n}}\left(\sum_{j=1}^{M} \alpha_{j} \beta_{i j} \sum_{t=1}^{T} P_{i}(t) \Delta t+\sum_{q=1}^{Q} \sum_{l=1}^{L} \alpha_{l q} \alpha_{q} N U M_{i} S_{D G}^{i}\right),
$$

where $M$ is the number of pollutants in the system; $\alpha_{j}$ is the cost of dealing with pollution $j ; \beta_{i j}$ is the coefficient of the equipment $i$ generating the pollutant $j$ when the equipment is working; $P_{i}(t)$ is energy output of equipment $i$ at time $t ; Q$ is the number of pollutants which can be purified by the plant; $\alpha_{q}$ is 
the coefficient representing the ability of plants to purify pollutants $j ; \alpha_{l q}$ is the cost of dealing with pollution $q ; L$ is the number of pollutants purified by the land.

There is a state subsidy policy for solar and wind energy in China, and according to the official policy, $\mathrm{C}_{s u}$ is shown in

$$
\mathrm{C}_{s u}=\sum_{i=1}^{n} \sum_{k=1}^{K} \sum_{t=1}^{T} P_{D G}^{\mathrm{i}} \Delta t C^{k}+\sum_{\mathrm{t}=1}^{T} P_{b u y}^{t} C_{\text {buy }}^{t}-\sum_{\mathrm{t}=1}^{T} P_{\text {sell }}^{t} C_{\text {sell }}^{t}
$$

where $K$ is the number of new energy subsidies; $C^{k}$ is the amount of subsidy based on the corresponding new energy subsidy policy $k ; P_{b u y}^{t}$ is the power purchased from the power grid at time $t ; C_{b u y}^{t}$ is the price of power purchased from the power grid at time $t ; P_{\text {sell }}^{t}$ is the power sold to the power grid at time $\mathrm{t}$; $C_{\text {sell }}^{t}$ is the price of power sold to the power grid at time $t$.

\section{References}

1. Li, Y.J.; Xia, Y. DES/CCHP: The best utilization mode of natural gas for China's low carbon economy. Energy Policy 2013, 53, 477-483. [CrossRef]

2. Cho, H.J.; Mago, P.D.; Luck, R.; Chamra, L.M. Evaluation of CCHP systems performance based on operational cost, primary energy consumption, and carbon dioxide emission by utilizing an optimal operation scheme. Appl. Energy 2009, 86, 2540-2549. [CrossRef]

3. Gu, W.; Wu, Z.; Wang, R. Multi-objective optimization of combined heat and power microgrid considering pollutant emission. Dianli Xitong Zidonghue 2012, 36, 177-185. (In Chinese)

4. Kuang, J.Y.; Zhang, C.H.; Li, F.; Sun, B. Dynamic Optimization of Combined Cooling, Heating, and Power Systems with Energy Storage Units. Energies 2018, 11, 2288. [CrossRef]

5. Wang, J.; Dai, W.; Zhou, Y.X. Multi-types of distributed generators planning based on free search algorithm. In Proceedings of the 5th IEEE International Conference on Electric Utility Deregulation, Restructuring and Power Technologies, DRPT 2015, Changsha, China, 26-29 November 2015.

6. Wang, C.S.; Hong, B.W.; Guo, L.; Zhang, D.J.; Liu, W.J. A general modeling method for optimal dispatch of combined cooling, heating and power microgrid. Zhongguo Dianji Gongcheng Xuebao 2013, 33, 26-33. (In Chinese)

7. Wang, L.; Lu, J.; Wang, W.; Ding, J. Feasibility analysis of CCHP system with thermal energy storage driven by micro turbine. Energy Procedia 2017, 105, 2396-2402. [CrossRef]

8. Shao, Y.Y.; Chen, B.M.; Xiao, H.M.; Qin, F.G.F. Discussion on Performance Evaluation Method of Distributed Combined Cooling, Heating, and Power System. J. Therm. Sci. 2019, 28, 1212-1220. [CrossRef]

9. Hu, R.; Ma, J.; Li, Z.K.; Lu, Q.; Zhang, D.H.; Qian, X. Optimal allocation and applicability analysis of distributed combined cooling-heating-power system. Dianwang Jishu 2017, 41, 418-425. (In Chinese)

10. Ma, X.Y.; Wu, Y.W.; Fang, H.L.; Sun, Y.Z. Optimal sizing of hybrid solar-wind distributed generation in an islanded microgrid using improved bacterial foraging algorithm. Zhongguo Dianji Gongcheng Xuebao 2011, 31, 17-25. (In Chinese)

11. Li, M.; Mu, H.L.; Li, N.; Ma, B.Y. Optimal design and operation strategy for integrated evaluation of CCHP (combined cooling heating and power) system. Energy 2016, 99, 202-220. [CrossRef]

12. Wang, J.J.; Jing, Y.Y.; Zhang, C.F. Optimization of capacity and operation for CCHP system by genetic algorithm. Appl. Energy 2010, 87, 1325-1335. [CrossRef]

13. Wang, J.J.; Zhai, Z.Q.; Jing, Y.Y.; Zhang, C.F. Particle swarm optimization for redundant building cooling heating and power system. Appl. Energy 2010, 87, 3668-3679. [CrossRef]

14. Liu, Y.; Luo, Y. Optimal design of distributed CCHP system. In Proceedings of the 2011 International Conference on Transportation, Mechanical, and Electrical Engineering, TMEE 2011, Changchun, China, 16-18 December 2011.

15. Huang, H.; Liang, D.P.; Tong, Z. Integrated energy micro-grid planning using electricity, heating and cooling demands. Energies 2018, 11, 2810. [CrossRef] 
16. Luo, X.J.; Fong, K.F. Development of multi-supply-multi-demand control strategy for combined cooling, heating and power system primed with solid oxide fuel cell-gas turbine. Energy Convers. Manag. 2017, 154, 538-561. [CrossRef]

17. Wang, J.; Ye, X.; Li, Y.; Gui, X.Q.; Guo, H.L. An energy efficiency evaluation method of distributed CCHP system based on attribute theory for optimal investment strategy. Energy Procedia 2018, 152, 95-100. [CrossRef]

18. Singh, S.; Singh, M.; Kaushik, S.C. Feasibility study of an islanded microgrid in rural area consisting of PV, wind, biomass and battery energy storage system. Energy Convers. Manag. 2016, 128, 178-190. [CrossRef]

19. Lorestani, A.; Gharehpetian, G.B.; Nazari, M.H. Optimal sizing and techno-economic analysis of energy- and cost-efficient standalone multi-carrier microgrid. Energy 2019, 178, 751-764. [CrossRef]

20. Huicochea, A.; Rivera, W.; Gutiérrez-Urueta, G.; Bruno, J.C.; Coronas, A. Thermodynamic analysis of a trigeneration system consisting of a micro gas turbine and a double effect absorption chiller. Appl. Therm. Eng. 2011, 31, 3347-3353. [CrossRef]

21. Dong, X.F.; Quan, C.; Jiang, T. Optimal planning of integrated energy systems based on coupled CCHP. Energies 2018, 11, 2621. [CrossRef]

22. Wang, J.J.; Fu, C.; Yang, K.; Zhang, X.T.; Shi, G.H.; Zhai, J. Reliability and availability analysis of redundant BCHP (building cooling, heating and power) system. Energy 2013, 61, 531-540. [CrossRef]

23. Lai, C.S.; Jia, Y.; Xu, Z.; Lai, L.L.; Li, X.; Cao, J.; McCulloch, M.D. Levelized cost of electricity for photovoltaic/biogas power plant hybrid system with electrical energy storage degradation costs. Energy Convers. Manag. 2017, 153, 34-47. [CrossRef]

24. Li, Y.; Liang, W.H.; Tan, R.S. Optimal design of installation capacity and operation strategy for distributed energy system. Appl. Therm. Eng. 2017, 125, 756-766. [CrossRef]

25. Luo, Z.; Yang, S.; Xie, N.; Xie, W.W.; Liu, J.X.; Souley Agbodjan, Y.; Liu, Z.Q. Multi-objective capacity optimization of a distributed energy system considering economy, environment and energy. Energy Convers. Manag. 2019, 200, 112081. [CrossRef]

26. Saman, S.; Mohamad, H.M.; Mehri, M. Modeling a novel CCHP system including solar and wind renewable energy resources and sizing by a CC-MOPSO algorithm. Appl. Energy 2016, 184, 375-395.

27. Lee, K.Y.; Park, J.B. Application of particle swarm optimization to economic dispatch problem: Advantages and disadvantages. In Proceedings of the 2006 IEEE PES Power Systems Conference and Exposition, PSCE 2006, Atlanta, GA, USA, 29 October-1 November 2006.

28. Zhan, Z.H.; Zhang, J.; Li, Y.; Chung, H.S.H. Adaptive Particle Swarm Optimization. IEEE Trans. Syst. Man Cybern. Part B Cybern. 2009, 39, 1362-1381. [CrossRef] 